\title{
Recovery of hypothalamo-pituitary-adrenal
} axis suppression during treatment with inhaled corticosteroids for childhood asthma

This article was published in the following Dove Press journal: Journal of Asthma and Allergy

\author{
Arundoss Gangadharan' \\ Paul McCoy ${ }^{2}$ \\ Aye Phyo' \\ Michael P McGuigan ${ }^{3}$ \\ Poonam Dharmaraj' \\ Renuka Ramakrishnan' \\ Paul S McNamara ${ }^{2,4}$ \\ Joanne Blair' \\ 'Department of Endocrinology, \\ 2Department of Respiratory Medicine, \\ Alder Hey Children's Hospital, \\ Liverpool, ${ }^{3}$ Department of Paediatrics, \\ Countess of Chester Hospital NHS \\ Foundation Trust, ${ }^{4}$ Institute in the \\ Park, University of Liverpool, Alder \\ Hey Children's Hospital, Liverpool, \\ UK
}

Objective: To describe recovery of adrenal insufficiency in asthmatic children treated with inhaled corticosteroids (ICS) and cortisol replacement therapy.

Design: Retrospective, observational study.

Patients: A total of 113 patients, 74 male; age 10.4 (3.3-16.5) years; beclomethasone-equivalent ICS dose, $800 \mu \mathrm{g},(100-1,000)$, tested by low dose short Synacthen (tetracosactide) test (LDSST), were studied. Test results were classified by basal and peak cortisol concentration: "normal" (basal $>100 \mathrm{nmol} / \mathrm{L}$, peak $>500 \mathrm{nmol} / \mathrm{L}$ ), "suboptimal" (basal $>100 \mathrm{nmol} / \mathrm{L}$, peak 350-499 $\mathrm{nmol} / \mathrm{L}$ ), "abnormal" (basal $<100 \mathrm{nmol} / \mathrm{L}$ and/or peak $<350 \mathrm{nmol} / \mathrm{L}$ ). Patients with suboptimal results received hydrocortisone during periods of stress only, and those with abnormal responses received daily hydrocortisone, increased during periods of stress. A total of 73 patients $(68 \%)$ had $\geq 2$ LDSSTs over 2.2 years $(0.2-7.7)$.

Measurements: Change in cortisol response to repeat LDSST (movement between diagnostic groups, difference in basal and peak cortisol $>15 \%$ [ $2 \times$ the inter-assay coefficient of variation]), change in BMI and height standard deviation score (SDS).

Results: Baseline test results were abnormal in 17 patients (15\%) and all of them had repeat tests. In 13 patients $(76 \%)$, test results improved (normal in six, suboptimal in seven) and four (24\%) remained abnormal. Baseline tests results were suboptimal in 54 patients ( $48 \%$ ), of whom $50(93 \%)$ were retested. Repeat tests were normal in 36 patients $(72 \%)$, remained suboptimal in $11(22 \%)$, and were abnormal in three $(6 \%)$. Baseline tests results were normal in 42 patients, of whom six patients (14\%) were retested. Results remained normal in three $(50 \%)$, were suboptimal in two (33\%), and abnormal in one (17\%). Basal and peak cortisol levels increased by $>15 \%$ in $33 / 73$ (45\%) and 42/73 (57\%) patients, respectively, and decreased by $>15 \%$ in $14 / 73$ $(19 \%)$ and $7 / 73(10 \%)$, respectively. There was no significant change in height or BMI SDS.

Conclusion: Recovery of adrenal function is common and occurs during continued ICS and cortisol replacement therapy.

Keywords: HPA axis recovery, adrenal suppression, childhood asthma, inhaled steroids (ICS), LDSST

\section{Introduction}

Asthma is the commonest chronic disorder of childhood, affecting 14\% of children worldwide, with wide geographical variation in prevalence. ${ }^{1}$ The use of inhaled corticosteroids (ICS) is recommended from step two of the British Thoracic Society (BTS) guidelines for the management of asthma. ${ }^{2}$ The side-effect profile of ICS therapy has been reported widely. ${ }^{3-9}$ Hypothalamo-pituitary-adrenal (HPA) axis suppression is reported in $20 \%-40 \%$ of unselected cohorts of children, ${ }^{3-7}$ including those treated
Correspondence: Joanne Blair Department of Endocrinology, Alder Hey Children's NHS Foundation Trust, East Prescot Road, Liverpool LI 4 5AB, UK Tel +44 I5 I 525 528 I

Email jo.blair@alderhey.nhs.uk 
with beclomethasone equivalent $200 \mu \mathrm{g} / \mathrm{day},{ }^{8}$ the starting dose recommended by BTS. ${ }^{2}$ Adrenal crisis and death has been reported in rare cases. ${ }^{4,7,9,10}$

The optimal surveillance and management protocols for children at risk of adrenal insufficiency during ICS therapy is a matter of ongoing discussion, and the need for further research was highlighted in a recent review article from the Pediatric Endocrine Society Drugs and Therapeutics Committee. ${ }^{11}$ To date, there are very few data reporting recovery of HPA axis suppression during ICS therapy. ${ }^{12-16}$ Patel et al described the recovery of adrenal function in a small case series of patients who presented acutely with adrenal crisis or insidiously with poor growth. ${ }^{7}$ A case report showed complete recovery of adrenal insufficiency and catch-up growth in a teenager following cessation of ICS therapy, ${ }^{8}$ and recovery of the HPA axis has also been reported in a small group of children when oral prednisolone was stopped or changed to ICS. ${ }^{17}$

We have reported adrenal function in children with asthma, treated with ICS, tested with a simplified low dose short tetracosactide test (LDSST) protocol previously, ${ }^{18}$ and a suggested management plan for children with secondary adrenal insufficiency. In this protocol, we have stratified hydrocortisone replacement therapy according to baseline and peak cortisol responses, because the clinical significance of modestly impaired results is uncertain. ${ }^{19}$ In doing so, we aimed to avoid overtreatment in children at lowest risk of adrenal crisis while ensuring treatment of children at greatest risk. Test results in which the basal cortisol concentration is $\geq 100 \mathrm{nmol} / \mathrm{L}$ and peak cortisol concentration is $\geq 500 \mathrm{nmol} / \mathrm{L}$ are classified as "normal". Peak cortisol concentrations of $350-499$ and $<350 \mathrm{nmol} / \mathrm{L}$ are classified as "suboptimal" and "abnormal" responses, respectively. Basal cortisol concentrations $<100 \mathrm{nmol} / \mathrm{L}$, when the test is performed before 10.00 , are also classified as "abnormal". Patients with a suboptimal response are treated with hydrocortisone $\left(20 \mathrm{mg} / \mathrm{m}^{2} / \mathrm{d}\right)$ during periods of acute illness only. Patients with an abnormal response are treated with daily hydrocortisone at a dose of $5-7.5 \mathrm{mg} / \mathrm{m}^{2} / \mathrm{d}$, and $20 \mathrm{mg} / \mathrm{m}^{2} / \mathrm{d}$ during acute illness.

The aim of this retrospective study was to describe recovery of adrenal function to "normal" in children with "suboptimal" or "abnormal" responses to the LDSST. We examined change in ICS doses during the observation period, to determine whether a reduction in steroid exposure was required for recovery of the HPA axis. Furthermore, we examined change in body mass index (BMI) and height standard deviation score (SDS) as evidence of glucocorticoid excess in children treated with hydrocortisone.

\section{Methods}

\section{Patients}

This retrospective study examined cortisol responses to the LDSST performed between 2008 and 2016 in children treated with ICS for asthma. The cohort comprised patients identified as being at increased risk of HPA axis suppression that is those patients receiving high doses of ICS doses, and those with symptoms suggestive of adrenal insufficiency. These patients were treated in a tertiary-level service in a specialist children's hospital. Moreover, we included an unselected group of pediatric patients with asthma, treated in secondary and tertiary-care centers, who had participated in a previous research study. ${ }^{18}$

Corticosteroid doses were recorded at the time of each LDSST, and expressed in microgram per day of beclomethasone dipropionate equivalent. ${ }^{16}$ The following dose equivalents were used: 1:1 for clenil modulite and budesonide; 2:1 for fluticasone, mometasone; and 1:4 for prednisolone., ${ }^{2,17}$

Patients treated with oral steroids continuously or on alternate days are discussed separately in view of the small numbers $(\mathrm{n}=6)$ and very high total steroid doses. These patients were tested on a day on which prednisolone was due, but before the dose was given, to allow the HPA axis to escape from prednisolone suppression.

\section{LDSST protocol}

Adrenal function was assessed using the simplified LDSST protocol as previously described. ${ }^{4,18}$ Briefly, blood is collected (0 min) upon peripheral venous cannula insertion, tetracosactide $\left(500 \mathrm{ng} / 1.73 \mathrm{~m}^{2}\right)$ is administered as an intravenous bolus, and three further blood samples are collected at 15 , 25 , and 35 minutes following tetracosactide administration.

All tests were undertaken in the morning.

\section{Cortisol assays}

An automated immunoassay analyzer (IMMULITE 2000 XPi, Siemens Health care, Camberley, UK) was used for measurement of serum cortisol. The intra-assay coefficient of variation is $<5 \%$ and inter-assay coefficient of variation is $<7.7 \%$.

Data were collected from computerized hospital data system. The study protocol was reviewed and approved by the Clinical Research Business Unit at Alder Hey Children's Hospital, Liverpool, UK who deemed that, as anonymized data were used in this retrospective, observational study, approval and informed consent from a Research Ethics Committee was not required. However, a formal ethical approval from the Liverpool local research ethics committee (Liver- 
pool Children's Research Ethics Committee) was obtained for the unselected group of asthma patients who were part of previous research study (Reference-07/H100/63). ${ }^{18}$

\section{Data analysis}

In patients with two or more LDSSTs, we analyzed change between the first baseline test and the most recent test. We described movement between diagnostic groups, given the clinical relevance of this outcome. Moreover, we described the number of patients in whom basal and peak cortisol changed by $>15 \%$ - twice the inter-assay coefficient of variation. Furthermore, we assessed change in height and BMI SDS as evidence of an adverse effect of hydrocortisone replacement therapy.

Statistical calculations were performed using SPSS (IBM Corp. Released 2013. IBM SPSS Statistics for Macintosh, Version 22.0. Armonk, NY: IBM Corp). A $p$-value $<0.05$ was considered significant. Statistical calculations including subgroup analysis were carried out to assess the relationship between basal and peak cortisol concentrations, the outcomes of LDSSTs and ICS doses. Wilcoxon signed-rank test was used to assess the differences between the variables in subgroup analyses.

\section{Results \\ Patient demographics}

Data were available for 113 patients, of whom 74 (65\%) were male. Seventy-three (65\%) were selected on the basis of high levels of ICS exposure or symptoms of adrenal insufficiency. Forty patients $(35 \%)$ were from an unselected cohort of pediatric patients with asthma who had participated in our previous study. ${ }^{18}$

The median (range) age at the time of the first LDSST was $10.4(3.3-16.5)$ years, and duration of follow-up was 1.3 $(0-7.7)$ years. Seventy-three patients $(68 \%)$ had more than one LDSST, with the median number of tests per patient being $2.7(2-7)$.

\section{ICS doses}

The median (range) ICS dose at the time of the first LDSST was $800(100-1,000) \mu \mathrm{g}$ and, at the final LDSST, $500(100-2,000)$ $\mu \mathrm{g}$. Changes in ICS dose for individual patients are shown in Table S1. Although the median steroid dose at the final followup point was less than the initial dose, this failed to reach statistical significance. Median ICS dose was lower in boys than girls: ICS dose $500(100-1,000) \mu \mathrm{g}$ and $450(100-1,200)$ $\mu \mathrm{g}$ at baseline and final LDSST, respectively, in boys, versus $800(200-1,000) \mu \mathrm{g}$ and $800(200-2,000) \mu \mathrm{g}$ in girls $(p=0.048)$.

Patient characteristics are described in Table 1.

\section{LDSST outcomes}

\section{Baseline test}

Seventeen patients $(15 \% ; 12$ male; median age [range] 8.6 [3.3-16.5] years) had an abnormal result, 54 patients $(48 \%$; 37 male; 10.9 [4.7-15.6] years) had a suboptimal result, and 42 (37\%; 25 male; 10.4 [3.8-14.8] years) patients had a normal result on their first test. Among those with an abnormal result, basal cortisol levels were $<100 \mathrm{nmol} / \mathrm{L}$ in nine patients. Characteristics of patients in each group, at baseline and at the time of the most recent LDSST, are given in Table 2.

\section{Outcomes of follow-up LDSST}

\section{Patients with an initial abnormal result}

All $17(100 \%)$ patients with an abnormal result on the first test underwent follow-up LDSST. Cortisol response on repeat testing was normal in six patients (35\%), suboptimal in seven patients $(41 \%)$, and in remained abnormal in four patients $(24 \%)$. In the nine patients in whom basal cortisol was $<100$ $\mathrm{nmol} / \mathrm{L}$ on the first test, repeat test results were normal in three, suboptimal in five, and remained abnormal in one.

\section{Patients with an initial suboptimal result}

A total of 50/54 (93\%) patients underwent a further LDSST, of which $36(72 \%)$ were normal. Eleven $(22 \%)$ patients

Table I Patient characteristics

\begin{tabular}{|c|c|c|c|}
\hline Patient characteristics & All patients & One LDSST only & $\geq 2$ LDSST \\
\hline Total/male (\%) & II $3 / 74(65 \%)$ & $40 / 24(60 \%)$ & $73 / 50(68 \%)$ \\
\hline Median (range) age (years) & $10.4(3.3-16.5)$ & $9.8(3.8-14.8)$ & $10.8(3.3-15.6)$ \\
\hline Median (range) follow-up period (years) & I.3 (0-7.7) & NA & $2.2(0.2-7.7)$ \\
\hline Total number of LDSSTs & 238 & 40 & 198 \\
\hline Average number of tests/patient & $2.1(I-7)$ & 1.0 & $2.7(2-7)$ \\
\hline ICS-start ( $\mu g /$ day $)$ & $800(100-1,000)$ & $500(100-1,000)$ & $800(2001,000)$ \\
\hline ICS-final ( $\mu g /$ day) & $500(100-2,000)$ & & $750(100-2,000)$ \\
\hline Ht SDS - start & $-0.3(-3.3$ to +2.8$)$ & $-0.4(-3.3$ to +2.8$)$ & $-0.2(-3.0$ to +2.8$)$ \\
\hline Ht SDS - final & $-0.3(-2.4$ to +2.9$)$ & & $-0.3(-2.4$ to +2.9$)$ \\
\hline BMI SDS - start & $+0.7(-2.0$ to +3.6$)$ & $+1.0(-1.8$ to +3.6$)$ & $+0.6(-2.0$ to +3.2$)$ \\
\hline BMI SDS - final & $+0.7(-1.7$ to +3.1$)$ & & $+0.7(-1.7$ to +3.1$)$ \\
\hline
\end{tabular}

Abbreviations: LDSST, low dose short tetracosactide test; ICS, inhaled corticosteroid; Ht, height; SDS, standard deviation score; BMI, body mass index. 
Table 2 Patients characteristics classified according to cortisol concentrations on the first LDSST

\begin{tabular}{|c|c|c|c|}
\hline Group characteristics & Normal $(\geq 500 \mathrm{nmol} / \mathrm{L})$ & Suboptimal (350-499 nmol/L) & Abnormal (<350 nmol/L) \\
\hline Number (\% of total) & $42(37 \%)$ & $54(48 \%)$ & $17(15 \%)$ \\
\hline Sex (male:female) & $25: 17$ & $37: 17$ & $12: 5$ \\
\hline Age at first test (years) & $10.4(3.8-14.8)$ & $10.9(4.7-15.6)$ & $8.6(3.3-16.5)$ \\
\hline Age at final test (years) & $10.8(3.8-14.8)$ & $14.0(5.8-18.4)$ & $12.4(7.4-18.1)$ \\
\hline F/U period (years) & $0(0-4.5)$ & $2.0(0-7.7)$ & $1.6(0.2-7.2)$ \\
\hline Total LDSSTs & 51 & 140 & 47 \\
\hline Average tests/person & 1.2 & 2.6 & 2.8 \\
\hline ICS dose at first LDSST ( $\mu \mathrm{g} /$ day) & $500(100-1,000)$ & $800(200-1,000)$ & $800(200-1,000)$ \\
\hline ICS dose at final LDSST ( $\mu \mathrm{g} /$ day) & $500(100-1,000)$ & $750(100-2,000)$ & $650(200-1,200)$ \\
\hline Ht SDS baseline & $-0.4(-3.3$ to +2.8$)$ & $-0.3(-3.0$ to +2.8$)$ & $-0.2(-1.7$ to +2.5$)$ \\
\hline Ht SDS final & $-0.4(-1.0$ to +0.7$)$ & $-0.3(-2.4$ to +1.5$)$ & $-0.7(-1.9$ to +2.9$)$ \\
\hline BMI SDS baseline & $+0.9(-1.8$ to +3.6$)$ & $+0.5(-2.0$ to +3.2$)$ & $+1.2(0$ to +3.1$)$ \\
\hline BMI SDS final & $+0.6(-0.2$ to +3.0$)$ & $+0.7(-1.3$ to +2.8$)$ & $+0.8(-1.7$ to +3.1$)$ \\
\hline
\end{tabular}

Abbreviations: F/U, follow-up; LDSST, low dose short tetracosactide test; ICS, inhaled corticosteroid; Ht, height; BMI, body mass index; SDS, standard deviation score.

continued to have a suboptimal result and three $(6 \%)$ patients had an abnormal result.

We were unable to identify repeat LDSST results for four patients in whom the cortisol response was suboptimal in the first LDSST. Among those, two patients were transferred to adult services and two moved out to another region. At the time of the first LDSST, the median age of these patients was 9.9 (5.8-14) years, $2 / 4$ were male, and ICS dose was $750(400-1,000) \mu \mathrm{g} /$ day. The median baseline cortisol on the first LDSST was $222(174-301) \mathrm{nmol} / \mathrm{L}$ and peak cortisol was 454 (417-499) $\mathrm{nmol} / \mathrm{L}$. All patients except one (female, 5.8 years of age at first LDSST, ICS dose $400 \mu \mathrm{g} /$ day, moved to a different region) were confirmed to be on appropriate steroid replacement therapy.

\section{Patients with an initial normal result}

In total, 6/42 (14\%) patients underwent a further LDSST because of ongoing clinical concern about the possibility of HPA axis suppression. Of these six patients, two had a suboptimal response, and one had an abnormal response.

Movement of patients between diagnostic groups is given in Figure 1.

\section{Change in basal and peak cortisol concentrations}

For all patients that underwent a repeat LDSST, mean \pm 1 SD basal cortisol concentration increased by $38 \pm 139 \mathrm{nmol} / \mathrm{L}-$ from $192 \pm 81$ to $244 \pm 113 \mathrm{nmol} / \mathrm{L}$. In $33 / 73(45 \%)$ showed $>15 \%$ increase, $14 / 73$ (19\%) showed $>15 \%$ decrease of basal cortisol response from the baseline, and 16/73 (22\%) showed less than $15 \%$ change in either response. In 10 patients (14\%) in whom repeat LDSST data were obtained from clinic correspondence, the baseline result was documented as being $>100 \mathrm{nmol} / \mathrm{L}$, but no absolute value was given.
Peak cortisol concentration increased by $86 \pm 130 \mathrm{nmol} / \mathrm{L}$ - from $423 \pm 100$ to $509 \pm 129 \mathrm{nmol} / \mathrm{L}$. A total of $42 / 73(57 \%)$ showed $>15 \%$ increase, $7 / 73(10 \%)$ showed $>15 \%$ decrease of peak cortisol response from the baseline, and 24/73 (33\%) showed less than 15\% change either way (Figure S1).

\section{Change in height and BMI SDS}

In the suboptimal group, median height and BMI SDS did not change between the first and last LDSST. In the abnormal group, the median height SDS fell from -0.2 to -0.7 , implying slow growth, and BMI SDS fell from +1.2 to +0.8 . These changes were not statistically significant.

\section{Oral steroid therapy}

Patients treated with oral steroid therapy are indicated by * in Figure 1.

The median age of these six patients was 8.8 years (range 5.8-12.2) and follow-up period was 7.0 years (4.3-7.9). The oral prednisolone dose range was $7.5-10 \mathrm{mg}$ on alternate days $(0.12-0.29 \mathrm{mg} / \mathrm{kg} / \mathrm{d}$, median $0.2 \mathrm{mg} / \mathrm{kg} / \mathrm{d})$. The median total steroid dose (both inhaled and oral) at the start was 20,900 $\mu \mathrm{g} /$ day (range 16,000-21,000) and, at the final follow-up, LDSST was 20,900 $\mu \mathrm{g}$ /day (range 11,000-21,500).

Among these six patients, three underwent repeat testing. Two patients had suboptimal results on the first LDSST, of which one remained suboptimal (asthma treatment: prednisolone $5 \mathrm{mg}$ on alternate days and ICS $1,000 \mu \mathrm{g} /$ day) and one became abnormal (asthma treatment: $10 \mathrm{mg}$ of oral prednisolone on alternate days, i.e., $0.1 \mathrm{mg} / \mathrm{kg} /$ day and ICS 1,500 $\mu \mathrm{g} /$ day). One patient, treated with $10 \mathrm{mg}$ oral prednisolone on alternate days, that is, $0.05 \mathrm{mg} / \mathrm{kg} /$ day and $1,000 \mu \mathrm{g} /$ day of ICS, had an abnormal LDSST result, which returned to 


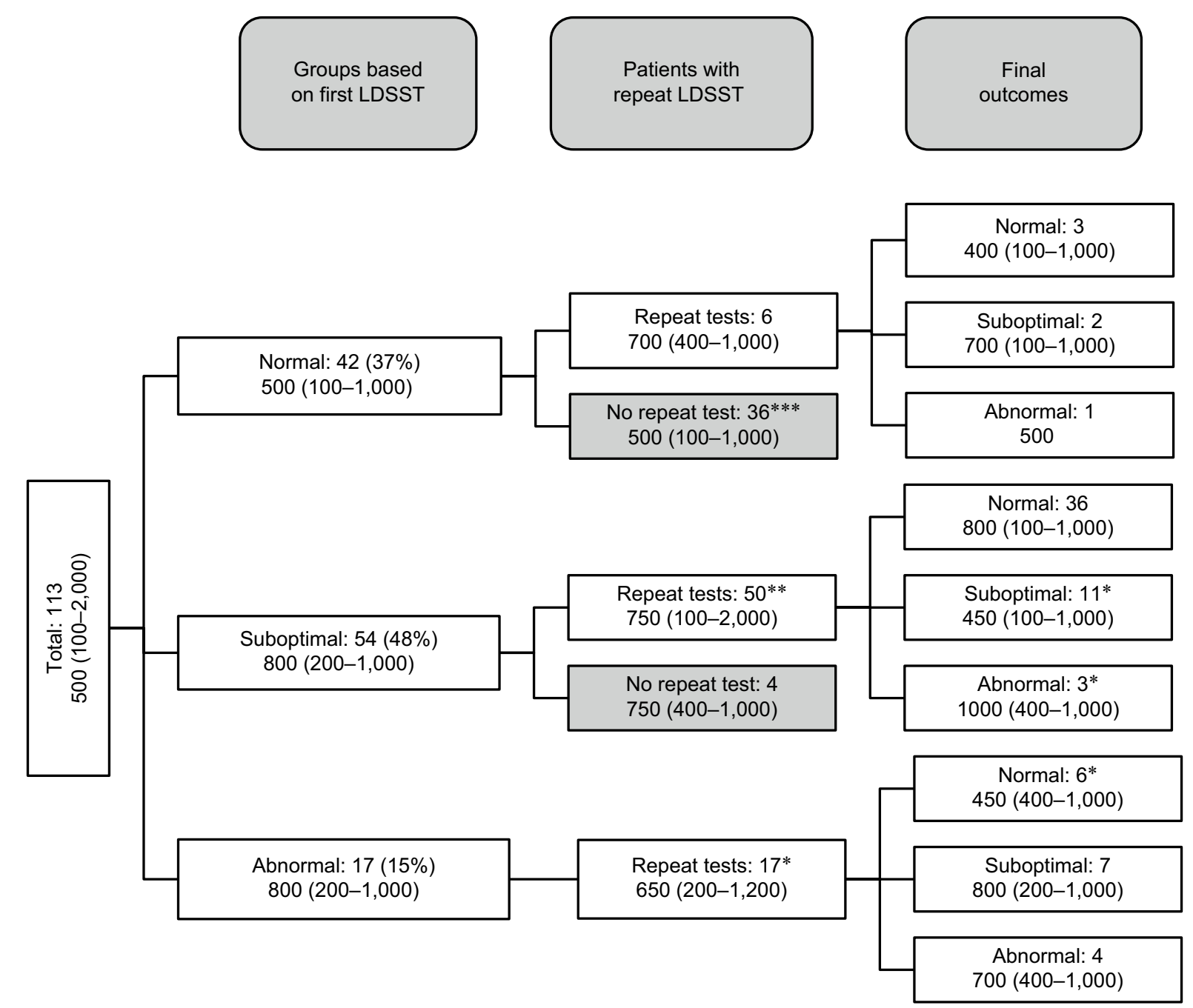

Figure I Movement of patients between diagnostic groups according to cortisol response to the final LDSST. Beclomethasone equivalent doses of ICS ( $\mu$ g/day) are shown at each time point: Median (range).

Note: Number of asterisk marks $(*)$ indicates the total number of patients on oral steroids in addition to ICS and their movements during follow-up.

Abbreviations: LDSST, low dose short tetracosactide test; ICS, inhaled corticosteroid.

normal on repeat testing. The remaining three patients had normal results and were not tested further.

\section{Discussion}

Biochemical evidence of adrenal suppression is common in children treated with ICS, and symptomatic adrenal insufficiency - including death from adrenal crisis - is described. ${ }^{4-7}$ However, much less is known about the recovery of HPA axis function during ICS therapy. To our knowledge, this is the largest cohort of patients described to date. These data are important; they should reassure clinicians and families that recovery of the HPA axis occurs in most patients and that treatment with hydrocortisone, in modest doses, is not associated with further deterioration in adrenal function.

There was no significant difference in ICS dose between those in whom the LDSST was normal and those with suboptimal and abnormal responses. This observation is consistent with our previous data from unselected cohorts of patients, ${ }^{18,20}$ and is surprising. This may reflect variable concordance with ICS treatment, differences in drug deposition in the lung and oral cavity, and variable drug absorption. It is important to note that we recorded only steroid therapy prescribed for asthma. Patients with other atopic conditions are likely to have been treated with intranasal or dermal steroids, which may also influence HPA axis activity. Finally, genetic determinants of glucocorticoid sensitivity and adverse effects have been reported widely, ${ }^{21,22}$ and it is likely that genetic factors also influence individual susceptibility to HPA axis suppression during ICS therapy as well as HPA axis recovery.

Seventy-three percent of patients with a suboptimal or an abnormal result to the first LDSST showed at least partial recovery of the HPA axis, including eight of the nine 
patients with baseline cortisol concentrations $<100 \mathrm{nmol} / \mathrm{L}$. Reasons for this high rate of recovery during ongoing ICS and hydrocortisone treatment are unclear. Impaired cortisol responses to the LDSST have been described in a small cohort of children with asthma before the introduction of ICS, with recovery during ICS treatment, ${ }^{23}$ and there is some evidence that adrenal function is impaired in children with longstanding atopic conditions. ${ }^{24}$ It is possible that mild impairments of adrenal function are a feature of atopy, with a natural history of recovery over time, although it seems unlikely that ICS plays no role in this process. Following a diagnosis of adrenal insufficiency, parents and patients attend an education appointment with an endocrine nursing specialist, in which they learn about the risk and clinical features of adrenal crisis as well as how to adjust hydrocortisone doses during periods of stress and, in patients with abnormal results, how to administer intramuscular hydrocortisone in the unconscious child. We speculate that parents who feel their child's asthma is well treated may reduce their doses of ICS in response to this information, and this may facilitate recovery of adrenal function.

In this study, $65 \%$ of patients were tested because they were felt to be at increased risk of HPA axis suppression because of their steroid exposure or because they complained of symptoms of adrenal insufficiency including lethargy, headache, abdominal pain, poor concentration, nausea, etc. The remaining $35 \%$ of patients were from a large, unselected cohort of patients, who were studied to determine the clinical utility of salivary biomarkers as screening tests for the identification of children with HPA axis suppression. ${ }^{18}$ In our previous study of unselected patients, LDSST results were abnormal in $4.5 \%$ and suboptimal in $37.5 \%$, compared to $15 \%$ and $48 \%$ in the selected cohort of patients reported in this article, suggesting use of steroid exposure and clinical features of adrenal insufficiency as a means of identifying those that should be tested is helpful.

In our center, we aim to retest patients with impaired or abnormal results every 6 months. However, the clinical status of the patient often determines the time of repeat test. In patients with "impaired" results who develop clinical features of adrenal insufficiency, LDSSTs will be conducted at an earlier stage, whereas LDSSTs are deferred in children in whom asthma symptoms deteriorate and increased doses of steroids are required. Standardizing diagnostic protocols, within these limitations, will be important in future, prospective work.

Patients with abnormal results were treated with low doses of hydrocortisone $\left(5-7.5 \mathrm{mg} / \mathrm{m}^{2} /\right.$ day, normal replacement doses being $8 \mathrm{mg} / \mathrm{m}^{2} /$ day), ${ }^{25}$ based on an assumption that there must be some systemic absorption of ICS to induce HPA axis suppression and a desire to maintain children in good health while minimizing an increase to their steroid burden. We observed a slowing of growth in those treated with daily hydrocortisone, but no gain in BMI SDS. A recent Cochrane review concluded that low- or medium-dose ICS results in a drop of longitudinal height by $0.48 \mathrm{~cm} /$ year and the adverse effect on the growth is likely to depend on the molecule of ICS that is used. ${ }^{26}$ This may account, in part, for some of the reduction in height SDS observed among our patients. Moreover, we observed a reduction in BMI SDS, which would be unexpected if the doses of hydrocortisone used in this treatment protocol were sufficient to cause a deceleration in growth.

Several tests are used for the assessment of the HPA axis. The short tetracosactide test is the most convenient and safest method of assessment, but has some limitations. ${ }^{19}$ The standard-dose short tetracosactide test (SDSST) uses a supra-physiological dose of tetracosactide $(250 \mu \mathrm{g})$ whereas the LDSST uses a more physiological dose (500 ng/1.73 $\left.\mathrm{m}^{2}\right)$ and produces similar peak cortisol response as the SDSST in healthy patients. ${ }^{16}$ Meta-analyses in both adult and pediatric populations have consistently found the LDSST to be more sensitive, and the SDSST to be more specific. ${ }^{12-16}$

Previously, a study by Gupta et al on the test-retest repeatability of the LDSST in 18 children with asthma reported only fair to good agreement when two LDSSTs were conducted with an interval of 1 month. ${ }^{27}$ However, it should be noted that in that study, samples were only collected at 20 and 30 minutes. The simplified LDSST used in our study was developed from raw data from LDSSTs undertaken in 400 children with asthma, sampled more intensively. ${ }^{4}$ Sampling at 15,25 , and 35 minutes enabled all children to be classified as having normal, impaired, or abnormal responses, whereas 20 and 30 minutes did not. This difference in test protocol may account, in part, for the poor test-retest reproducibility reported previously. ${ }^{4}$

The definition of a "normal" and "abnormal' response to the LDSST is based on studies conducted in healthy children and those known to be at high risk of adrenal impairment. ${ }^{19}$ A normal response is generally considered to have a peak cortisol $>500 \mathrm{nmol} / \mathrm{L}$, or an increment in cortisol of $>200 \mathrm{nmol} / \mathrm{L} .{ }^{19}$ However, there is a clear disparity in the high prevalence of biochemical abnormalities of the HPA axis and very low prevalence of symptoms of chronic adrenal insufficiency and adrenal crisis during ICS therapy for asthma. In the development of the protocol used for the management of patients in this study and those published 
previously, we carefully reviewed case reports and case series of adrenal crisis during ICS therapy in childhood, obtaining individual patient data from corresponding authors wherever possible..$^{7,9,10,28-31}$ In these studies, assessments of adrenal reserve included the LDSST, SDSST, and/or glucagon tests. All patients who were tested in the non-acute setting had peak cortisol values $<350 \mathrm{nmol} / \mathrm{L}$ on provocation testing, and generally $<200 \mathrm{nmol} / \mathrm{L}$. We, therefore, stratified our approach to adrenal replacement therapy, where only those with basal cortisol $<100 \mathrm{nmol} / \mathrm{L}$, and/or low peak cortisol concentrations $(<350 \mathrm{nmol} / \mathrm{L})$ should receive daily treatment, with those with peak cortisol concentrations between 350 and $499 \mathrm{nmol} / \mathrm{L}$ administered hydrocortisone only during periods of stress.

\section{Limitations}

We were unable to identity follow-up LDSST data for four patients with an initial suboptimal result, and the absolute values of the baseline cortisol concentration was not available for 10 patients. In a relatively small cohort of patients, these missing data may significantly influence the rates of adrenal recovery presented in this article.

We have no measure of concordance with either ICS or hydrocortisone, and it is important that relationships between doses of these medications and LDSST results are interpreted cautiously. Furthermore, we have not recorded any concomitant steroid medication use, such as intranasal or dermal steroids.

We did not measure clinical features of adrenal insufficiency objectively before testing, or following the introduction of hydrocortisone replacement therapy. For this reason, we are unable contribute to the discussion with regard to the clinical significance of modestly impaired cortisol responses to the LDSST. Symptoms of adrenal insufficiency are vague, are difficult to quantify, and can be attributed to many different causes. In order for this issue to be resolved, robust tools for the measurement and monitoring of clinical features of adrenal insufficiency in children and young people over time need to be developed. Such a tool would enable this important question to be addressed in a rigorous clinical study.

\section{Conclusion}

Suppression of the HPA axis is common in children using ICS. Although recovery of axis occurs in the majority of patients on ICS, the exact pathophysiology of HPA axis suppression in some and relative protection in others needs careful consideration. Robust clinical studies are required to determine which children should be tested and treated, to develop clinical tools to identify and monitor children with adrenal insufficiency, and to determine the optimal diagnostic and treatment protocols.

\section{Acknowledgments}

The authors would like to thank Drs Didi, Das, and Senniappan who generously shared their clinical data, Endocrine Nurse Specialists Zoe Yung, Lynne Hatchard, Pauline Blundell, and Jacqueline Parkes who performed the LDSST, and Drs Joseph and Lacy (Wirral University Teaching Hospital), Satish (Warrington and Halton Hospital Trust), and Robertson (Royal Blackburn Hospital) for their support in providing follow-up data.

\section{Disclosure}

The authors report no conflicts of interest in this work.

\section{References}

1. The Global Asthma Report 2014. Global burden of disease due to asthma. 2017. Available from: http://www.globalasthmareport.org/ burden/burden.php. Accessed 28 May, 2017.

2. Society BT. BTS/SIGN British guideline on the management of asthma | British Thoracic Society | Better lung health for all. 2017. Available from: https://www.brit-thoracic.org.uk/standards-of-care/guidelines/ btssign-british-guideline-on-the-management-of-asthma/. Accessed 28 May, 2017.

3. Priftis KN, Papadimitriou A, Gatsopoulou E, Yiallouros PK, Fretzayas A, Nicolaidou P. The effect of inhaled budesonide on adrenal and growth suppression in asthmatic children. Eur Respir J. 2006;27(2):316-320.

4. Paton J, Jardine E, McNeill E, et al. Adrenal responses to low dose synthetic ACTH (Synacthen) in children receiving high dose inhaled fluticasone. Arch Dis Child. 2006;91(10):808-813.

5. Broide J, Soferman R, Kivity S, et al. Low-dose adrenocorticotropin test reveals impaired adrenal function in patients taking inhaled corticosteroids. J Clin Endocrinol Metab. 1995;80(4):1243-1246.

6. Kannisto S, Korppi M, Remes K, Voutilainen R. Adrenal suppression, evaluated by a low dose adrenocorticotropin test, and growth in asthmatic children treated with inhaled steroids. J Clin Endocrinol Metab. 2000;85(2):652-657.

7. Patel L, Wales JK, Kibirige MS, Massarano AA, Couriel JM, Clayton PE. Symptomatic adrenal insufficiency during inhaled corticosteroid treatment. Arch Dis Child. 2001;85(4):330-334.

8. Shenoy SD, Swift PG, Cody D. Growth impairment and adrenal suppression on low-dose inhaled beclomethasone. J Paediatr Child Health. 2006;42(3):143-144.

9. Drake AJ, Howells RJ, Shield JP, Prendiville A, Ward PS, Crowne EC. Symptomatic adrenal insufficiency presenting with hypoglycaemia in children with asthma receiving high dose inhaled fluticasone propionate. BMJ. 2002;324(7345):1081-1082.

10. Todd GR, Acerini CL, Buck JJ, et al. Acute adrenal crisis in asthmatics treated with high-dose fluticasone propionate. Eur Respir J. 2002;19(6):1207-1209.

11. Kapadia CR, Nebesio TD, Myers SE, et al; Drugs and Therapeutics Committee of the Pediatric Endocrine Society. Endocrine effects of inhaled corticosteroids in children. JAMA Pediatr. 2016;170(2):163-170.

12. Ng SM, Agwu JC, Dwan K. A systematic review and meta-analysis of Synacthen tests for assessing hypothalamic-pituitary-adrenal insufficiency in children. Arch Dis Child. 2016;101(9):847-853.

13. Kazlauskaite R, Evans AT, Villabona CV, et al; Consortium for Evaluation of Corticotropin Test in Hypothalamic-Pituitary Adrenal Insufficiency. Corticotropin tests for hypothalamic-pituitary- adrenal insufficiency: a metaanalysis. J Clin Endocrinol Metab. 2008;93(11):4245-4253. 
14. Kazlauskaite R, Maghnie M. Pitfalls in the diagnosis of central adrenal insufficiency in children. Endocr Dev. 2010;17:96-107.

15. Dorin RI, Qualls CR, Crapo LM. Diagnosis of adrenal insufficiency. Ann Intern Med. 2003;139(3):194-204.

16. Magnotti M, Shimshi M. Diagnosing adrenal insufficiency: which test is best--the 1-microg or the 250-microg cosyntropin stimulation test? Endocr Pract. 2008;14(2):233-238.

17. Harrison BD, Rees LH, Cayton RM, Nabarro JD. Recovery of hypothalamo-pituitary-adrenal function in asthmatics whose oral steroids have been stopped or reduced. Clin Endocrinol (Oxf). 1982;17(2): $109-118$.

18. Blair J, Lancaster G, Titman A, et al. Early morning salivary cortisol and cortisone, and adrenal responses to a simplified low-dose short Synacthen test in children with asthma. Clin Endocrinol (Oxf). 2014; 80(3):376-383.

19. Park J, Didi M, Blair J. The diagnosis and treatment of adrenal insufficiency during childhood and adolescence. Arch Dis Child. 2016;101(9):860-865.

20. Hawcutt DB, Jorgensen AL, Wallin N, et al. Adrenal responses to a low-dose short synacthen test in children with asthma. Clin Endocrinol (Oxf). 2015;82(5):648-656.

21. Moreira RP, Gomes LG, Madureira G, Mendonca BB, Bachega TA. Influence of the A3669G glucocorticoid receptor gene polymorphism on the metabolic profile of pediatric patients with congenital adrenal hyperplasia. Int J Endocrinol. 2014;2014:594710.

22. Moreira RP, Gomes LG, Mendonca BB, Bachega TA. Impact of glucocorticoid receptor gene polymorphisms on the metabolic profile of adult patients with the classical form of 21-hydroxylase deficiency. PLoS One. 2012;7(9): e44893.
23. Priftis KN, Papadimitriou A, Anthracopoulos MB, et al. Adrenal function improves in asthmatic children on inhaled steroids: a longitudinal study. Neuroimmunomodulation. 2006;13(1):56-62.

24. Wamboldt MZ, Laudenslager M, Wamboldt FS, Kelsay K, Hewitt J. Adolescents with atopic disorders have an attenuated cortisol response to laboratory stress. J Allergy Clin Immunol. 2003;111(3):509-514.

25. Peters CJ, Hill N, Dattani MT, Charmandari E, Matthews DR, Hindmarsh PC. Deconvolution analysis of 24-h serum cortisol profiles informs the amount and distribution of hydrocortisone replacement therapy. Clin Endocrinol (Oxf). 2013;78(3):347-351.

26. Zhang L, Prietsch SO, Ducharme FM. Inhaled corticosteroids in children with persistent asthma: effects on growth. Evid Based Child Health. 2014;9(4):829-930.

27. Gupta A, Cheetham T, Jaffray C, Ullman D, Gibb I, Spencer DA. Repeatability of the low-dose ACTH test in asthmatic children on inhaled corticosteroids. Acta Paediatr. 2009;98(12):1945-1949.

28. Todd GR, Wright D, Ryan M. Acute adrenal insufficiency in a patient with asthma after changing from fluticasone propionate to budesonide. J Allergy Clin Immunol. 1999;103(5 Pt 1):956-957.

29. Macdessi JS, Randell TL, Donaghue KC, Ambler GR, van Asperen PP, Mellis CM. Adrenal crises in children treated with high-dose inhaled corticosteroids for asthma. Med J Aust. 2003;178(5):214-216.

30. Carrel AL, Somers S, Lemanske RF Jr, Allen DB. Hypoglycemia and cortisol deficiency associated with low-dose corticosteroid therapy for asthma. Pediatrics. 1996;97(6 Pt 1):921-924.

31. Kennedy MJ, Carpenter JM, Lozano RA, Castile RG. Impaired recovery of hypothalamic-pituitary-adrenal axis function and hypoglycemic seizures after high-dose inhaled corticosteroid therapy in a toddler. Ann Allergy Asthma Immunol. 2002;88(5):523-526. 


\section{Supplementary materials}

Table SI ICS doses of suboptimal and abnormal group

ICS at first and final LDSST tests: median (range) in microgram

$\begin{array}{ll}\text { Suboptimal group: ICS Abnormal group: ICS } & \text { Abro }\end{array}$

\begin{tabular}{|c|c|c|c|c|c|}
\hline Initial (A) & Final (B) & A-B & Initial (A) & Final (B) & A-B \\
\hline 500 & 500 & 0 & 500 & 500 & 0 \\
\hline 400 & 400 & 0 & 1,000 & 1,000 & 0 \\
\hline 500 & 400 & 100 & 800 & 400 & 400 \\
\hline 400 & 200 & 200 & 400 & 400 & 0 \\
\hline 800 & 800 & 0 & 400 & 400 & 0 \\
\hline 1,000 & 1,200 & -200 & 1,000 & $\mathrm{I}, 000$ & 0 \\
\hline 1,000 & 1,000 & 0 & 800 & 800 & 0 \\
\hline 1,000 & 1,000 & 0 & 1,000 & & 1,000 \\
\hline 1,000 & 400 & 600 & 400 & 400 & 0 \\
\hline 1,000 & 1,000 & 0 & 1,000 & 800 & 200 \\
\hline 200 & 200 & 0 & 800 & 800 & 0 \\
\hline 400 & 400 & 0 & 200 & 200 & 0 \\
\hline 500 & 1,000 & -500 & 800 & 1,200 & -400 \\
\hline 400 & 400 & 0 & 400 & 400 & 0 \\
\hline 1,000 & 1,000 & 0 & 1,000 & 1,000 & 0 \\
\hline 400 & 2,000 & $-1,600$ & 400 & 400 & 0 \\
\hline 1,000 & 800 & 200 & I,000 & 1,000 & 0 \\
\hline 400 & 400 & 0 & & & \\
\hline 1,000 & $\mathrm{I}, 000$ & 0 & & & \\
\hline 300 & 300 & 0 & & & \\
\hline 500 & 500 & 0 & & & \\
\hline 1,000 & 1,000 & 0 & & & \\
\hline 400 & 400 & 0 & & & \\
\hline 800 & 100 & 700 & & & \\
\hline 1,000 & 1,200 & -200 & & & \\
\hline 800 & 800 & 0 & & & \\
\hline 1,000 & 1,000 & 0 & & & \\
\hline 1,000 & 1,000 & 0 & & & \\
\hline 1,000 & 1,000 & 0 & & & \\
\hline 1,000 & 250 & 750 & & & \\
\hline 1,000 & 800 & 200 & & & \\
\hline 200 & 100 & 100 & & & \\
\hline 400 & 200 & 200 & & & \\
\hline 1,000 & 400 & 600 & & & \\
\hline 1,000 & 1,000 & 0 & & & \\
\hline 500 & 500 & 0 & & & \\
\hline 500 & 500 & 0 & & & \\
\hline 1,000 & & 1,000 & & & \\
\hline 400 & 400 & 0 & & & \\
\hline 1,000 & 1,000 & 0 & & & \\
\hline 1,000 & $\mathrm{I}, 500$ & -500 & & & \\
\hline 800 & 2,000 & $-1,200$ & & & \\
\hline 400 & 800 & -400 & & & \\
\hline 800 & 800 & 0 & & & \\
\hline 500 & 500 & 0 & & & \\
\hline 1,000 & 1,000 & 0 & & & \\
\hline 800 & 1,000 & -200 & & & \\
\hline 1,000 & 1,000 & 0 & & & \\
\hline 400 & 400 & 0 & & & \\
\hline 400 & 400 & 0 & & & \\
\hline 500 & 500 & 0 & & & \\
\hline 750 & 750 & 0 & & & \\
\hline 400 & 400 & 0 & & & \\
\hline 400 & 400 & 0 & & & \\
\hline $800(200-1,000)$ & $750(100-2,000)$ & $0(-1,600-1,000)$ & $800(200-1,000)$ & $650(200-1,200)$ & $0(-400-1,000)$ \\
\hline
\end{tabular}

Note: Median (range) in microgram/day are shown in bold.

Abbreviations: ICS, inhaled corticosteroid; LDSST, low-dose short tetracosactide test. 


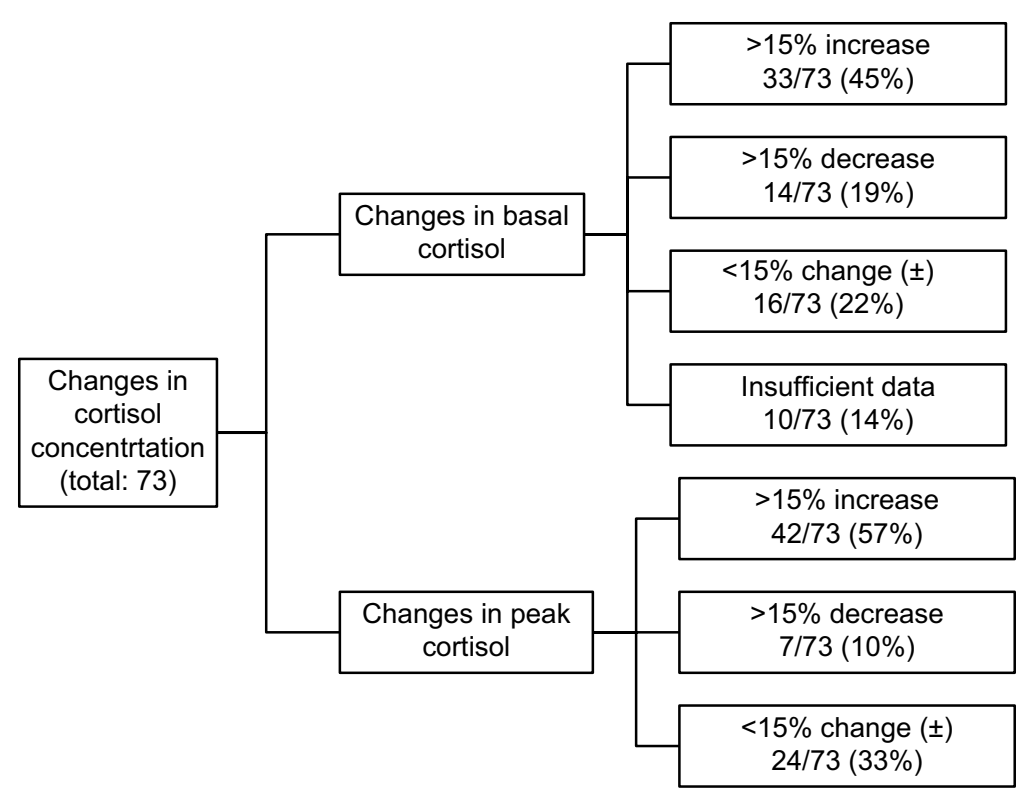

Figure SI Changes in basal and peak cortisol concentrations.

\section{Publish your work in this journal}

The Journal of Asthma and Allergy is an international, peer-reviewed open access journal publishing original research, reports, editorials and commentaries on the following topics: Asthma; Pulmonary physiology; Asthma related clinical health; Clinical immunology and the immunological basis of disease; Pharmacological interventions and
Dovepress

new therapies. This journal is included in PubMed. The manuscript management system is completely online and includes a very quick and fair peer-review system, which is all easy to use. Visit http://www. dovepress.com/testimonials.php to read real quotes from published authors. 